\title{
Urban architecture for the advancement of small-scale township enterprises: relevance of the scholarship
}

\author{
G. P. Setshedi \\ Department of Architecture, University of Pretoria, South Africa
}

\begin{abstract}
This paper reviews recent scholarship about strategies of urban architecture designed for the enhancement of small-scale home-based and non home-based township enterprises and establishes its relevance to the situation on the ground. Arguments in this paper are substantiated by architectural surveys conducted in government subsidised low-income houses in Ga-Rankuwa, a formerly black township or "location" located on the periphery of Pretoria, South Africa. The surveys focused on the architecture (modifications) of small-scale enterprises and characteristics of the built environment emerging as a result of pressures towards sustainable establishment of local small-scale enterprises. The sampled scholarship is reviewed in terms of research context, methodology, findings, strengths, weaknesses and ultimately relevance.
\end{abstract}

Keywords: urban design, architecture, housing, SMME, township enterprises, $R D P$.

\section{Introduction}

Townships, like Ga-Rankuwa with over (fig. 3), in South Africa evolved from the "locations", or otherwise the slum yards, which were used as reserves for black labourers or non-whites (i.e. 'redundant natives' or rather "Bantu of greater backwardness' as stated by Wepener [1] in Native Housing) at that time regarded as not worthy of sharing urban privileges. Such derogatory establishments were initiated decades preceding apartheid through legislation (Native Urban Act of 1923, Land Act of 1913, Slums Acts) but glorified and concretized by the apartheid regime. They were built on the urban periphery and linked to the cities through railway and road systems. Their planning, architecture and infrastructure 
were of sub-minimum standard. The architectural manifestations that were, during the era of segregation in South Africa, used as material demonstration to subject black people to counterproductive and inhumane living conditions continue to haunt the current urban fabric under the democratic dispensation.

The pressing needs for appropriate housing and infrastructure development were never addressed resulting in degradation and creation of squatter camps. Townships resembled concentration camps bearing no promise for further urban development and economic sustainability. Negative features common to formerly black South African townships are: high crime rate; the HIV-AIDS pandemic; slums and squatters settlements- which all induce a significant decline in urban development and investment. Most townships, to date, are yet to experience proper infrastructure development and systems considering the urban and population growth and inherent socio-economic difficulties. Today, they stand as enormous challenges of urban regeneration. Moreover, the current socio-spatial patterns and emerging urban architecture in townships require scientific acknowledgement for their contribution as far as urban livelihood is concerned.

Most townships in South Africa have growth potential comprising a substantial mass of capable labour force needed for increasing economic activity and productivity. As a result of high unemployment, a slow economic growth and a growing need for a highly skilled labour force, most people are forced to establish own businesses around their neighbourhood. These are classified as home and non-home based small-scale enterprises and constitute a significant feature of township livelihood. They are usually small informal economic units created and run by families for self-employment. So far, they have been tolerated by authorities and recognised for their contribution to the national economy, particularly considering the orthodox macroeconomic policies in South Africa, which have so far struggled to address the country's unemployment [2]. Though small-scale enterprises form an integral part of both the formal and informal sectors, this paper focuses only on the small-scale home-based businesses in the informal sector involved in, among others, light manufacturing, provision of services, retailing and construction related activities.

As observed by Tipple [3] in 1996 and still today, the architecture of housing extension in economically and socially depressed areas is yet to be adequately investigated. Urban architecture accommodating small-scale enterprises in lowincome areas is yet to be adequately and scientifically documented. For the kind of services they provide, their floor areas are relatively small. When these enterprises are part of the household, a need for extension arises, which are usually constructed from temporary or recycled materials (i.e. metal containers, corrugated iron, timber and brick). Even though most small-scale proprietors try to build and maintain add-ons of an acceptable standard, a lack of proper infrastructure and knowledge about architecture hold them back. This is as a result of a number of factors (i.e. inefficient local development strategies, infrastructure developments, delivery mechanisms, partnerships and participation strategies) but also exacerbated by the fact that professions in architecture were and continue to be unpopular among non-whites in South Africa. Moreover, the 
current breed of architectural designers struggles to comprehend such challenges and hence irrelevant solutions continue to occur. Most solutions lack context and diversity and ignore contemporary environmental issues because most people conducting research in townships are non-residents or lack appropriate knowledge about local vibes. Until recently architecture in South Africa has been considered a euro-centric discipline associated with the wealthy. Architects in South Africa have done well in commercial and domestic architecture, but not in social design [4]. The current government is placing emphasis and investment in the development of social and economic infrastructure induced by the country's needs and formalised by the South African Constitution and Bill of Rights. This is enough reason and incentive for architects to begin to seek for a new socially acceptable role.

When small-scale enterprises are introduced, their survival is hampered by inadequate infrastructure and lack of intellectual support (financial, management and technological know-how). For their accommodation, Yankson [5] states that one needs to understand how within the urban environment and space economy small-scale enterprises choose site of operation, characteristics of the selected site, operational aspects and the effect on the immediate environment, which all affect the nature of their architecture and urban space. According to Perera in Yankson [5], lack of suitable space for production and inefficient marketing inhibit the growth of small-scale businesses.

\section{Architecture of home-based enterprises}

The aim of this section is to begin to comprehend the sophistication and the impact of the architecture of extensions on the environment and attempt to establish the extent to which they are beneficial to the users and the urban environment in general. A representative sample of peculiar modifications from Ga-Rankuwa, formerly black Township established early in the 1960's on the periphery of Pretoria about $25 \mathrm{~km}$ away [6], is discussed. Ga-Rankuwa has around 69000 inhabitants and is divided into old and new zones (the former provided under the previous apartheid regime while the latter following the democratic dispensation). From the old zones (1,2,3,4,5,6,7,15 and 16) houses on all streets were observed with particular emphasis on those comprising of business activity that require architectural extensions and in the new units (Ga-Rankuwa View) Reconstruction and Development Program (RDP) houses were observed with most modifications recorded but with particular emphasis on those comprising home-based enterprises.

\subsection{Old zones}

Before the democratic dispensation in 1994 in South Africa the design of houses for the majority of the so-called "urbanised Natives or Bantu" was exclusively a (white) government affair [7-9]. Houses in the old zones represent another depressing mass housing schemes of the famous apartheid sub-economic house types NE51/6 and NE51/9 (fig. 1) (non-European version 6 \& 9 of 1951) 
introduced in 1951 by the National Building Research Institute (NBRI) [10]. These houses stand today as cultural and historical artifacts, a reminder of how evil and racism could subdue minds and hearts of those perceived at the time to be intellects or professors in architecture and the built environment. Today, most of these buildings have been extended and modified in such a way that their contribution to the field of (grounded) architecture needs be accorded credit. In accommodating small-scale enterprises, most of the houses appear to be awkwardly placed on site such that they inhibit rather than encourage extensions. Most of the original, if not all, NE51/6 or NE51/9 house types were placed in the center of the plot making it extremely difficult to extent substantially to any direction (fig. 2). Defying all odds, inhabitants of these houses appear determined to turn the spell cast on them by these architecturally inappropriate structures and urban spaces.
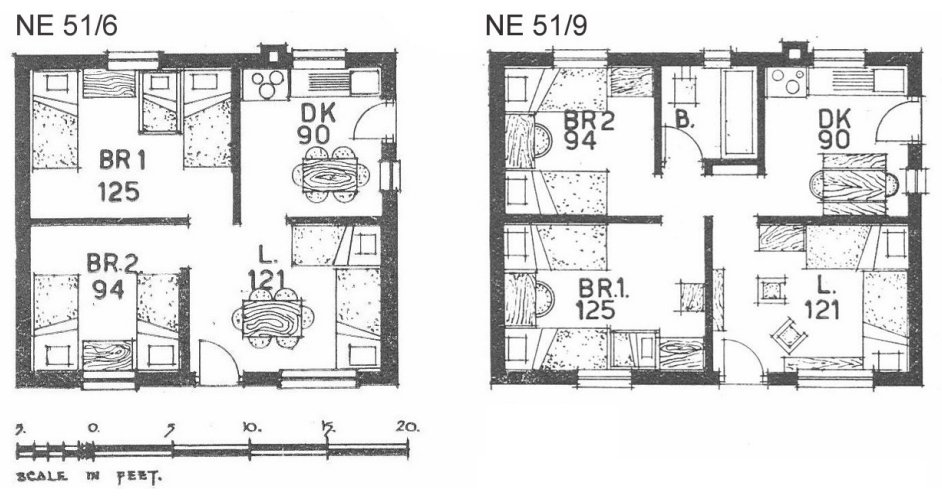

Figure 1: $\quad$ House Type NE 51/6 \& 51/9 (NBRI [10]).

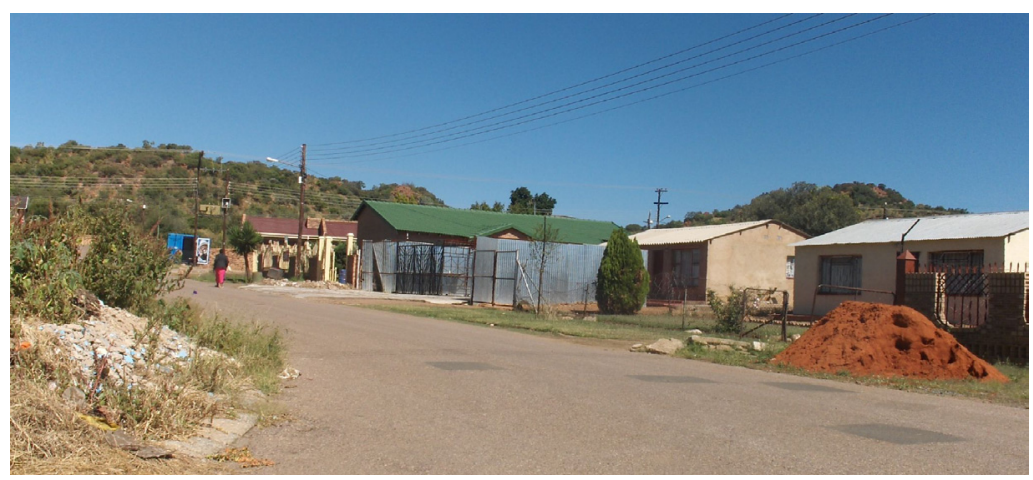

Figure 2: $\quad$ NE51/6 house type with car workshop on street façade (photo by author).

\subsection{New zone}

This section presents results from an architectural documentation process conducted on 1300 government-provided $30 \mathrm{~m}^{2}$ RDP houses in Ga-Rankuwa 
(fig. 3). According to the South African National Department of Housing [11], since the initiation of the RDP program in South Africa following the democratic election in 1994 over 1,793,124 houses were completed or under construction. RDP houses in Ga-Rankuwa, like many others throughout the country, were built on a one-site-one-house concept with plot sizes averaging $250 \mathrm{~m}^{2}(12.5 \times 20 \mathrm{~m})$ arranged on a grid. They comprise of just one room plus a $1.8 \times 1.8 \mathrm{~m}$ bathroom. The survey was warranted by the fact that since the inception of the RDP in 1994, many occupants or beneficiaries continue to complain about the state of the houses resulting in plethora of 'illegal' and undocumented architectural modifications. From the documentation survey, focusing on the quality of urban and architectural spaces, constructions integrity and functionality of the houses, it becomes apparent that the various patterns of modifications and additions signify an inevitable trend towards sustainable settlements.

The initial RDP houses in Ga-Rankuwa were built on a one-site-one-house concept with plot sizes averaging $250 \mathrm{~m}^{2}(12.5 \times 20 \mathrm{~m})$ arranged on a grid. These houses comprise of only one room plus $1.8 \times 1.8 \mathrm{~m}$ bathroom with bath, hand basin and WC. Most were placed on sites haphazardly as the grid dictated. Among peculiar construction features of these buildings are: 140mm external walls from maxi bricks $(140 \times 90 \times 290 \mathrm{~mm})$ with one coat of cemcrete to external walls and another of bagwash to internal walls with no plaster. Roofs were built from lipped channel rafters, covered with cranked $0.45 \mathrm{~mm}$ galvanised corrugated iron roof sheets at $9.5^{\circ}$ pitch resting. No bargeboards, facias, ceilings or skirtings have been installed. Electricity was installed approximately a year after initial occupation.

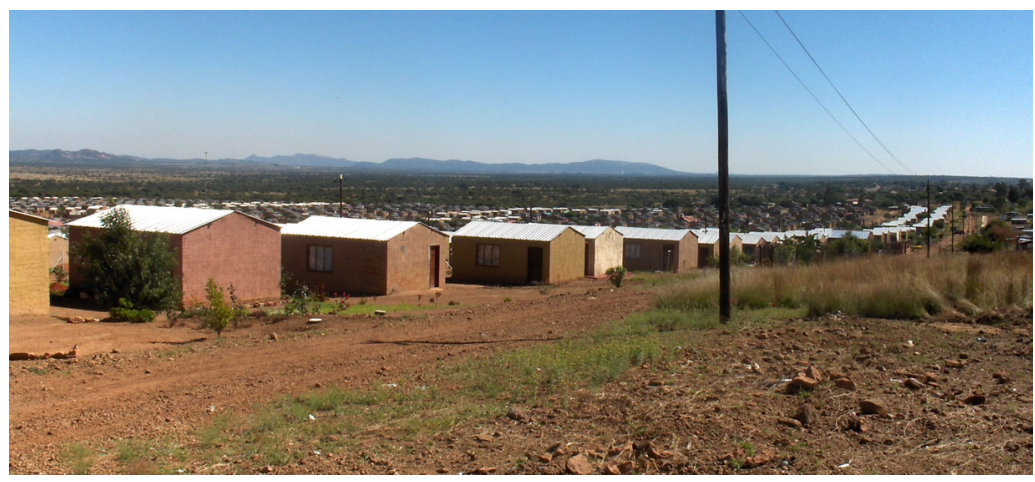

Figure 3: General view of Ga-Rankuwa View (RDP Settlement) (photo by author).

\subsection{Observations}

Approximately four years after completion and occupation, most houses show signs of decay such as oxidation in bricks; structural cracks from (shifting) rafters and unstable lintels and disintegrating abutments; and unstable 
foundations; etc. Most additions were created to provide much needed private spaces and for commercial purposes such as entertainment outlets (shebeens) and spaza (kiosk) shops (fig. 4).

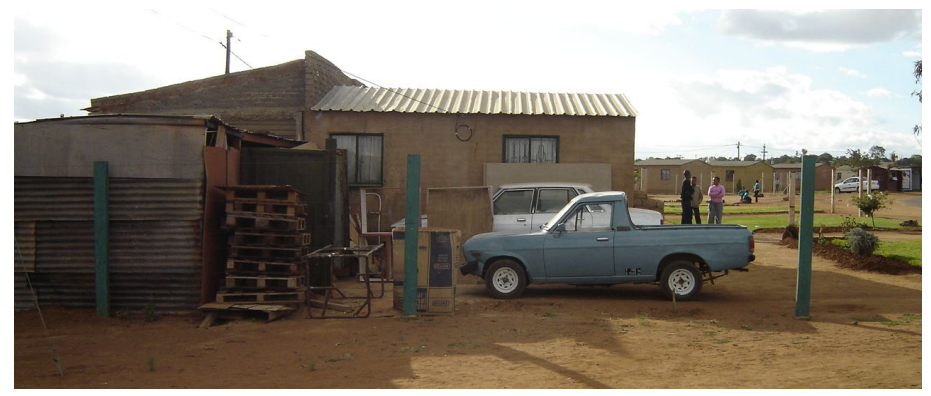

Figure 4: $\quad$ Extended RDP house plus carpenter's workshop (photo by author).

Extended houses were observed to determine: whether extensions are temporary or permanent determined mainly by the types of building materials; whether extensions are attached or separated from the original RDP house; position of the house in relation to north and side of extensions; and the size (large, smaller or approximately equal) of the extension in relation to the original. Of the 1300 RDP houses, 135 (10.4\%) have been extended signifying the degree at which residents are despondent at the architecture and size of government-subsidised houses. While less than $7 \%$ of the extended houses were still under construction, the majority had roofs. As a result of the residents not employing architects (usually too expensive to consult for this low-income group) or draftsmen for extensions nor inform local authorities, the quality of construction in many instances is of inferior quality though the understanding and creation of architectural spaces is of a peculiar nature. $122(90 \%)$ of the 135 extended houses have been built as permanent structures (using brick for walls and corrugated irons on timber for roofing) while the remaining are built mainly from recycled materials such as corrugated sheets, timber and bricks.

The size and degree at which extensions are carried out depends on a number of factors but limited by finances and location of the original house on plot. About $45(33 \%)$ of additions have a total area smaller (far less than $15 \mathrm{~m}^{2}$ ) than the original RDP house while $29(21 \%)$ are of the same size. The majority of the additions (about 62 or $46 \%$ ) are relatively larger than the original house. In most cases the integration of additions is executed in such a manner that one can still identify the original (fig. 4). Citing the unfortunate regarding the above data, the rate at which houses in this settlement are extended renders statistics in this research irrelevant a few months subsequent to the survey. Recalling Yankson's discussions about site selection and location of such small-scale enterprises, it is apparent that home-based enterprises in this settlement depend largely on other means such as mouth-to-mouth advertisement or explicit modifications of the house to market products. 


\section{Scholarship review}

Literature relating directly to the establishment of informal architecture and especially for informal enterprises is evidently lacking. This section offers a critical interpretation and interrogation of empirical research and scholarship pertaining to the development of a sustainable urban architecture for the enhancement of small-scale township enterprises. The relevance of the reviewed scholarship is selected and their relevance evaluated against the architecture on the ground (or survey above).

\subsection{Small-scale home and non-home based enterprises}

In the journal issue Cities, Kigochie [12] explores the impact of rehabilitation programmes on home-based enterprises in squatter settlements in the Mathare 4A, Nairobi. The article is concerned about the efficacy of rehabilitation projects in squatter settlements and affordability. The research methodology employed in the article appears to have produced anticipated outcomes regardless of underlying authenticity concerns. It discovered that: proprietors agreed that new structures are much better built, organised and identifiable, with subsequent increases in sales; reduction of operation costs; improved private and distinguishable operation spaces; and security of tenure contributed significantly to the modifications and improvements of homes (contradicting the study by Yankson below). New structures created jobs and fostered a diverse economy even though proprietors experienced expansion problems, probably because of inflexible architectural designs and increased competition.

This is among the crucial points observed during the survey in Ga-Rankuwa even though lack of finances became apparent as an important inhibit factor. Also, in both the Ga-Rankuwa survey and Kigochie's study, the architectural designs were not flexible enough to cater for future natural family and business growth. The period of survey of Kigochie's study was unfortunately short and need to be enriched by a longitudinal or cross-sectional study.

Yankson [13] conducted a survey concerned with the unmonitored rapid growth and unsuitable location of the informal small-scale production and service enterprises in the metropolitan area in Accra, Ghana and discovered that: The location characteristics and factors influencing the site selection of the enterprises include: appropriateness of enterprise to the area; high percentage ran businesses from in or around the house; availability of customers (mainly pedestrian) who could easily reach the outlet; majority of enterprise operators were tenants household heads and family members of the landlords; and a high percentage of enterprises were located along the main roads of the city.

It is emphasised that enterprises based in houses and neighbourhoods could not migrate to desired and more productive locations, due to a lack of alternative sites. Another positive of home-based enterprises is that women could combine their business activities with household duties. Lastly, it was discovered that small-scale production and service enterprises do not follow the normative models of industrial locations and that the site selection is not determined, as 
thought by municipal authorities and some academics, by security of tenure, customer-entrepreneur relationship and the price of work spaces. But also, the working environment of the small-scale economic enterprises was characterised by: (1) lack of extendable workshop spaces in home-based enterprises, compared to those outside residential neighbourhoods; and (2) more than half of the enterprises had electricity, water, and paved roads but were poorly served with sanitation. Services to enterprises outside residential areas were the worst. Environmental effects of the enterprises were severe when considering air pollution from processing and production of different products, and the generation of solid and water waste.

\subsection{Urban design and architecture}

Hubbard [14] acknowledges the significance of urban design in providing quality built environments and good designs derived from local context and relevance, but raises concerns about the process of urban design, driven towards a pictorial mode rather than as a setting of everyday life. The socio-economic context manifesting itself is unique in every setting. The urban built environment must meet the needs of local inhabitants and promote their normative social interactions, cultural norms and environmental aspects [15].

Mahmud [16] explores the way women create and transform domestic spaces for various economic activities in Dhaka bustees (illegal or unauthorised housing for the poor or low-income groups). According to Pacione in Mahmud [16], the use of home spaces as work place saves time and money, which is absolutely necessary for the smooth running of a business. Mahmud confirms that accessibility of market centres, access to urban services, relative spatial control and home tenure contribute significantly to the success of entrepreneurship.

In conclusion, Mahmud discovered that: the degree of changing domestic spaces or alteration indicates freedom of living and the security of tenure; the type of home-based production is recommended depending to a certain degree on the flexibility of spaces; most bustee spaces allow accommodation for production, consumption and rental (housing); proprietors in government-owned properties are more advantaged than those in private properties because they pay no rentals and need not apply for permission to modify inhabited structures; and that the increase of home-based enterprises trickles down towards the improvement and investment in the urban physical space.

\section{Conclusion}

So far the reviewed scholarship provides no clear indication as to the best practice that may lead to the betterment of the subject. One may comfortably suggest frameworks through which further research may be undertaken to further comprehend the subject. As a result, this paper suggests a systematic synthesis of the highlighted areas of the assessed literature above to be researched further otherwise local development initiatives, especially in Third World countries, are prone to fail. Among the closely related articles on the subject, Yankson appears 
to provide a more comprehensive approach as far as site selection and accommodation of local enterprises in the urban areas are concerned. An important distinction in Yankson's research to is that the research is conducted in a densely populated area in the metropolitan area of Accra, Ghana and likewise a similar survey methodology could be used to understand and compare the accommodation characteristics and criteria of enterprises in relatively lowdensity and dislocated peri-urban townships in South Africa. In addition Mahmud's research on the architectural qualities of bustees in Dhaka provides an insight about the documentation process of architectural spaces of home and non-home based enterprises, which forms a sound basis for a similar and slightly advanced research on local enterprises. The application of these methodologies in township enterprises may further reveal the environmental, technological, scientific, social and artistic considerations crucial for establishing a locally derived urban design strategy.

So far there has never been a satisfactory urban design technique or architecture that is capable of addressing problems of accommodation of the informal sector in an urban environment in Third World countries. Therefore, this paper recommends a bottom-up approach, which develops urban design and architectural strategies informed by the local conceptions of space, culturally diverse and environmental context, and locally justified research findings supported by relevant international scholarship. This socially driven design process can be complemented by Hamdi's [17] housing strategic methods of: flexibility (adaptability of the design to growth and change); participation (user participation in decision-making); and enablement (cultivate an environment in which habitation is constantly enhanced).

\section{References}

[1] Wepener, F.J., Psychological Approach (Part II). Native Housing, eds. P.H. Connell, C. Irvine-Smith, K. Jonas, R. Kantorowich, \& F.P. Wepener, Johannesburg. Witwatersrand University Press. pp. 50-86, 1939.

[2] Bond, P., Basic infrastructure for socio-economic development, environmental protection and geographical desegregation: South Africa's unmet challenge. Geoforum, 30(1), pp. 43-59, 1999.

[3] Tipple, A. G., Housing extensions as sustainable development. Habitat International, 20(3), pp. 367-376, 1996.

[4] Uduku, N. O., Architecture and the community- African perspectives. Architecture SA, 25(2), pp. 23-26, 1995.

[5] Yankson, W. E., Accommodating the informal economic units in the urban built environment: petty commodity enterprises in Accra metropolitan area. Third World Planning Review, 22(3), pp. 313-334, 2000.

[6] Chipkin, C.M., Preparing for Apartheid: Pretoria and Johannesburg (Chapter 7). Architecture of the Transvaal, eds. R.C. Fisher, S. Le Roux \& E. Maré, Pretoria: University of South Africa, pp. 149-174, 1998. 
[7] Connell, P.H., Irvine-Smith, C., Jonas, K., Kantorowich, R. \& Wepener, F.P., (eds.) Native Housing, Johannesburg: Witwatersrand University Press, 1939.

[8] Calderwood, D. M., Principles of mass housing, Pretoria: CSIR, 1964.

[9] Chipkin, C.M., Preparing for Apartheid: Pretoria and Johannesburg (Chapter 7). Architecture of the Transvaal, eds. R.C. Fisher, S. Le Roux \& E. Maré, Pretoria: University of South Africa, pp. 149-174, 1998.

[10] Calderwood, D.M.\& Connell, P.H., Minimum standards of accommodation for the housing of non-Europeans in South Africa (Appediture B). Research studies on the cost of urban Bantu housing, eds. National Building Research Institute (South Africa) \& South African Council for Scientific and Industrial Research, 1954.

[11] South African National Department of Housing, www.housing.gov.za.

[12] Kigochie, P.W., Squatter rehabilitation projects that support home-based enterprises create jobs and housing. Cities, 18(4), pp. 223-233, 2001.

[13] Yankson, W.E., Accommodating the informal economic units in the urban built environment: petty commodity enterprises in Accra metropolitan area. Third World Planning Review, 22(3), pp. 313-334, 2000.

[14] Hubbard, P., Urban design and local economic development. Cities, 12(4), pp. 243-251, 1995.

[15] Saleh, M.A.E., The evaluation of planning \& urban theory from the perspective of vernacular design: MOMRA initiatives in improving Saudi Arabian neighbourhoods. Land Use Policy, 18(3), pp. 179-190, 2001.

[16] Mahmud, S., Women and the transformation of domestic spaces for income generation in Dhaka bustees. Cities, 20(5), pp. 321-329, 2003.

[17] Hamdi, N., Housing without houses, New York: Van Nostrand Reinhold, 1991. 